\title{
Double Switch Biodegradable Porous Hollow Trinickel Monophosphide Nanospheres for Multimodal Imaging Guided Photothermal Therapy
}

Yang Liu, ${ }^{\dagger, t}$ Wenyao Zhen, ${ }^{+,}$Yinghui Wang, ${ }^{*},+$ Jianhua Liu, "Longhai Jin," Tianqi Zhang," Songtao Zhang, ${ }^{\dagger}$ Ying Zhao, ${ }^{\dagger, t} N a$ Yin, ${ }^{\dagger, t}$ Rui Niu, ${ }^{\dagger, t}$ Shuyan Song, ${ }^{\dagger, t}$ Lei Zhang, ${ }^{,+\dot{t}}$ and Hongjie Zhang ${ }^{*}, \dot{t}, \dot{t}$

†State Key Laboratory of Rare Earth Resource Utilization, Changchun Institute of Applied Chemistry, Chinese Academy of Sciences, Changchun, Jilin, 130022, P. R. China

University of Science and Technology of China, Hefei, Anhui, 230026, P.R. China ${ }^{\S}$ State Key Laboratory of Electroanalytical Chemistry, Changchun Institute of Applied Chemistry, Chinese Academy of Sciences, Changchun, Jilin, 130022, P. R. China

"Department of Radiology, The Second Hospital of Jilin University, Changchun, Jilin, 130041, Changchun, P. R. China

Corresponding author:

*E-mail (Y. Wang): yhwang@ciac.ac.cn

*E-mail (H. Zhang): hongjie@ ciac.ac.cn

Tel.: +8643185262127

Fax: +8643185698041 


\section{Experimental Section}

Chemicals and Reagents: Nickel chloride $\left(\mathrm{NiCl}_{2} \cdot 6 \mathrm{H}_{2} \mathrm{O}\right)$, ammonia solution $\left(\mathrm{NH}_{3} \cdot \mathrm{H}_{2} \mathrm{O}\right)$, sodium hypophosphite monohydrate $\left(\mathrm{NaH}_{2} \mathrm{PO}_{2}\right)$, hydrochloric acid $(\mathrm{HCl})$, anhydrous sodium acetate $(\mathrm{NaAc})$, and potassium hydroxide $(\mathrm{KOH})$ were purchased from Beijing Chemical Reagents Company (Beijing, China). Bovine serum albumin (BSA) was purchased from Beijing Gentihold Biological Technology Co., Ltd. (Beijing China).

Preparation of $\mathrm{Ni}_{3} \mathrm{P}: \mathrm{Ni}_{3} \mathrm{P}$ is synthesized based on previous literature. In detail, $\mathrm{NiCl}_{2} \cdot 6 \mathrm{H}_{2} \mathrm{O}(5 \mathrm{~g}), \mathrm{NaH}_{2} \mathrm{PO}_{2}(24.4 \mathrm{~g})$, and $\mathrm{NaAc}(2.9 \mathrm{~g})$ were dissolved in $100 \mathrm{~mL}$ of deionized water. Then, we adjusted the $\mathrm{pH}$ value of the mixture to 8 by adding $\mathrm{KOH}$ solution. After $\mathrm{N}_{2}$ purged for $20 \mathrm{~min}$, the mixture was heated to $90^{\circ} \mathrm{C}$ for $1 \mathrm{~h}$. Then, black precipitates were obtained by way of centrifugation at $8000 \mathrm{rpm}$ for 5 minutes. The products were washed several times with $\mathrm{NH}_{3} \cdot \mathrm{H}_{2} \mathrm{O}$ and deionized water. Then, black products were calcined under $\mathrm{N}_{2}$ at $400^{\circ} \mathrm{C}$ for $1 \mathrm{~h}$ (heating rate: $10^{\circ} \mathrm{C} \mathrm{min}^{-1}$ ). Finally, the calcined product was stirred in concentrated hydrochloric acid for $24 \mathrm{~h}$. Black precipitates were obtained with the method of centrifugation, and washed three times with deionized water.

Surface ligand modification: Firstly, $0.2 \mathrm{~g}$ of BSA was dissolved in deionized water. Then, $\mathrm{Ni}_{3} \mathrm{P}$ aqueous solution was added dropwise and stirred for $12 \mathrm{~h}$. Then, products were acquired by way of centrifugation, washed three times with deionized 
water. Finally, the mixture was further dialyzed in deionized water for $48 \mathrm{~h}$ to remove excess BSA.

Photothermal properties of NiP PHNPs: $0.5 \mathrm{~mL}$ of NiP PHNPs aqueous solution (100 $\left.\mu \mathrm{g} \mathrm{mL}^{-1}\right)$ was placed in cuvette, and then a temperature probe was inserted into the NiP PHNPs aqueous solution. Finally, NiP PHNPs aqueous solutions were irradiated with $1064 \mathrm{~nm}$ continuous laser with different power densities $(0.1,0.2,0.3$, 0.5 , and $0.75 \mathrm{~W} \mathrm{~cm}^{-2}$ ). The temperature of NiP PHNPs aqueous solution was recorded by a temperature probe every $30 \mathrm{~s}$. At the same time, the temperature was recorded by an infrared thermal imaging camera (FLIR T420, Fluke, USA).

Thermal stability of NiP PHNPs: $0.5 \mathrm{~mL}$ of NiP PHNPs aqueous solution was irradiated with $0.5 \mathrm{~W} \mathrm{~cm}^{-2}$ of $1064 \mathrm{~nm}$ continuous laser for $10 \mathrm{~min}$, and then naturally cooled to room temperature. The above process is repeated four times.

Molar extinction coefficient of NiP PHNPs: The Molar extinction coefficient of NiP PHNPs is calculated by the following equation ${ }^{1}$ :

$\varepsilon=\left(\mathrm{AV} \rho \mathrm{N}_{\mathrm{A}}\right) /\left(\mathrm{LC}_{\mathrm{wt}}\right)$

A: UV-vis absorption of NiP PHNPs aqueous solution at $1064 \mathrm{~nm}$. V: the volume of NiP PHNPs, we consider the NiP PHNPs approximation as a sphere. So, $\mathrm{V}=$ $4 / 3 \times \pi \times \mathrm{r}^{3}=2.68 \times 10^{-16} \mathrm{~cm}^{3} . \rho:$ the density of $\mathrm{Ni}_{3} \mathrm{P}\left(7.821 \mathrm{~g} \mathrm{~L}^{-1}\right) . \mathrm{N}_{\mathrm{A}}$ : Avogadro's constant $\left(6.02 \times 10^{23} \mathrm{~mol}^{-1}\right)$. L: the length of the light through the NiP PHNPs aqueous solution $(1 \mathrm{~cm}) . \mathrm{C}_{\mathrm{wt}}$ : the weight concentration of NiP PHNPs. 
So, $\varepsilon=\left(A V \rho N_{A}\right) /\left(\mathrm{LC}_{\mathrm{wt}}\right)=1.577 \times 10^{10} \mathrm{M}^{-1} \mathrm{~cm}^{-1}$

Photothermal conversion efficiency of NiP PHNPs: Photothermal conversion efficiency of NiP PHNPs is calculated by the following equation ${ }^{1}$ :

$\eta=\left[\mathrm{hS}\left(\mathrm{T}_{\max }-\mathrm{T}_{\text {surr }}\right)-\mathrm{Q}_{\text {Dis }}\right] /\left[\mathrm{I}\left(1-10^{-\mathrm{A} 1064}\right)\right] \times 100 \%$

$\mathrm{hS}=\left(\Sigma \mathrm{m}_{\mathrm{i}} \mathrm{C}_{\mathrm{p}, \mathrm{i}}\right) / \tau_{\mathrm{s}}$

$\mathrm{t}=\tau_{\mathrm{s}} \times(-\ln \theta)$

$\theta=\left(\mathrm{T}-\mathrm{T}_{\text {surr }}\right) /\left(\mathrm{T}_{\max }-\mathrm{T}_{\text {surr }}\right)$

$\mathrm{T}_{\max }$ : equilibrium temperature. $\mathrm{T}_{\text {surr: }}$ ambient temperature. QDis: heat loss due to absorption of light by the container. I: power density of $1064 \mathrm{~nm}$ continuous laser. A: UV-vis absorption of NiP PHNPs aqueous solution at $1064 \mathrm{~nm} . \tau_{\mathrm{s}}$ : the sample system time constant (172.3 s). h: heat transfer coefficient, S: the irradiated area.

So, $\eta=\left[\mathrm{hS}\left(\mathrm{T}_{\max }-\mathrm{T}_{\text {surr }}\right)-\mathrm{Q}_{\text {Dis }}\right] /\left[\mathrm{I}\left(1-10^{-\mathrm{A} 1064}\right)\right] \times 100 \%=56.8 \%$

DOX loading: $3 \mathrm{~mL}$ of DOX $\left(1 \mathrm{mg} \mathrm{mL}^{-1}\right)$ solution was added by dropwise into NiP PHNPs ( $\left.1 \mathrm{mg} \mathrm{mL}^{-1}\right)$ while stirring. After stirring for $24 \mathrm{~h}$, BSA aqueous solution was added. After $12 \mathrm{~h}$, the mixture was centrifuged and washed with deionized water. The DOX loading was measured by measuring the UV-vis absorption spectra of centrifuged supernatant. The DOX loading content (LC) is calculated by the following equation:

$$
\mathrm{LC} \%=\left(\mathrm{m}_{\text {total }}-\mathrm{m}_{\text {supernatant }}\right) / \mathrm{m}_{\text {total }} \times 100 \%
$$


DOX releasing: NiP PHNPs-DOX was dissolved in $5 \mathrm{~mL}$ of PBS with different pH values (6.5 and 7.4). Then, the NiP PHNPs-DOX solution were transferred to the dialysis bag (molecular weight cutoff $=8000$ ). Dialysis bags were then immersed in $20 \mathrm{~mL}$ of PBS with different $\mathrm{pH}$ values (6.5 and 7.4) and stirred at $37^{\circ} \mathrm{C}$. At the selected point in time $(0,1,2,3,4,5,6,7,8,9,10,11,12$, and $24 \mathrm{~h}), 1 \mathrm{~mL}$ of solution were taken out and replaced with $1 \mathrm{~mL}$ of the fresh PBS. The DOX content was measured by UV-vis absorption spectra. DOX releasing of NIR II responses (1064 $\mathrm{nm}$ continuous laser, $1 \mathrm{~W} \mathrm{~cm}^{-2}$ ) were measured as a same way.

Cytotoxicity Measurement of NiP PHNPs: We inoculated HeLa cells into 96-well plates for $24 \mathrm{~h}$, and then different concentrations of NiP PHNPs medium solution were added for another $24 \mathrm{~h}$. Then we washed HeLa cells three times with PBS, and CCK-8 medium solution $(100 \mu \mathrm{L})$ was added. Four hours later, we used microplate reader to measure its absorbance at $450 \mathrm{~nm}$.

In Vitro Chemo/Photothermal Therapy: We inoculated HeLa cells into 96-well plates for 24h, and then different concentrations of NiP PHNPs and NiP PHNPs-DOX (dose of DOX: $200 \mu \mathrm{g} \mathrm{mg}^{-1}$ ) medium solution $\left(0,12.5,25,50\right.$, and $100 \mu \mathrm{g} \mathrm{mL}^{-1}$ ) were added. After $12 \mathrm{~h}$, we washed HeLa cells three times with PBS, and $200 \mu \mathrm{L}$ of medium was added. Then, HeLa cells were illuminated by $0.5 \mathrm{~W} \mathrm{~cm} \mathrm{~cm}^{-2}$ of $1064 \mathrm{~nm}$ continuous laser for $10 \mathrm{~min}$, and further cultured for 24 hours. Finally, the activity of HeLa cells was tested by CCK- 8 assay. In addition, we used Calcein AM and PI to stained HeLa cells, and observed their activity with confocal microscopy. 
In vitro and in vivo MR imaging: MRI imaging was measured by clinical MRI scanner (GE Discovery MR750 3.0T). We put NiP PHNPs aqueous solution with different concentrations $(0,0.04,0.08,0.16,0.32,0.63,1.25$, and $2.5 \mathrm{mM})$ in a 1.5 mL centrifuge tube for in vitro MRI. We injected $200 \mu \mathrm{L}$ of NiP PHNPs solution into the tail of the tumor-bearing mouse, and the MRI signals of tumor was measured before and after intravenously injection.

In vitro and in vivo PA imaging: PA imaging was measured by MSOT imaging technique (MSOT inVision 128, iThera Medical GmbH, Munich, Germany). In vitro PA imaging of NiP PHNPs aqueous solution with different concentrations was measured. We injected $200 \mu \mathrm{L}$ of NiP PHNPs solution into the tail of the tumor-bearing mouse, and the in vivo PA signals was measured before and after injection. The mice were scanned repeatedly under pulsed lasers of different wavelengths $(680,715,750,785,820,855$, and $890 \mathrm{~nm})$.

In vivo Chemo/photothermal therapy: We implanted U14 cells under the axilla of female Balb/c mouse to establish tumor model. We randomly divided tumor-bearing mice into five groups: (A) PBS (control group), (B) $1064 \mathrm{~nm}$ laser group, (C) NiP PHNPs-DOX (CT group), (D) NiP PHNPs +1064 nm laser (PTT group), and (E) NiP PHNPs-DOX + $1064 \mathrm{~nm}$ laser group (CT/PTT group). Tumor-bearing mice (group C and E) were intravenously injected $200 \mu \mathrm{L}$ of NiP PHNPs-DOX (dose of DOX: $200 \mu \mathrm{g} \mathrm{mg}^{-1}$ ) solution, and mice (group D) were intravenously injected NiP PHNPs solution. After that, tumor-bearing mice were 
illuminated by $1064 \mathrm{~nm}$ continuous laser for $10 \mathrm{~min}$. During the treatment, we recorded the body weight and tumor volume of the mice every two days. On the 15 th day, we dissected the mice and weighed the quality of the tumors to assess the therapeutic effect.

Biodistribution of NiP PHNPs: We injected $200 \mu \mathrm{L}$ of NiP PHNPs solution into the tail of the tumor-bearing mouse. Heart, liver, spleen, lung, kidney, and tumor were obtained by dissecting mice after injection (1, 3, 7, 14, and 21 days). Then, we used aqua regia to soak heart, liver, spleen, lungs, kidney, and tumor of mice. Ni content in organs and tumors was measured by ICP-AES.

Histology Staining: We dissected mice to obtain their tumor, heart, liver, spleen, lung, and kidney. After a series of processes, these organs and tumor tissues were cut into $4 \mu \mathrm{m}$ thick sections. Finally, these sections were stained with hematoxylin and $\operatorname{eosin}(\mathrm{H} \& \mathrm{E})$. 


\section{Results and Discussion}

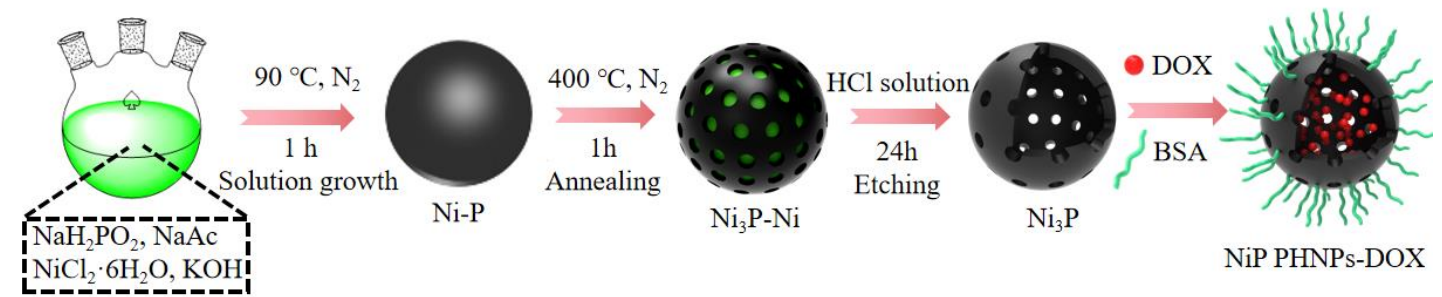

Figure S1. Schematic illustration of the synthesis of NiP PHNPs-DOX.

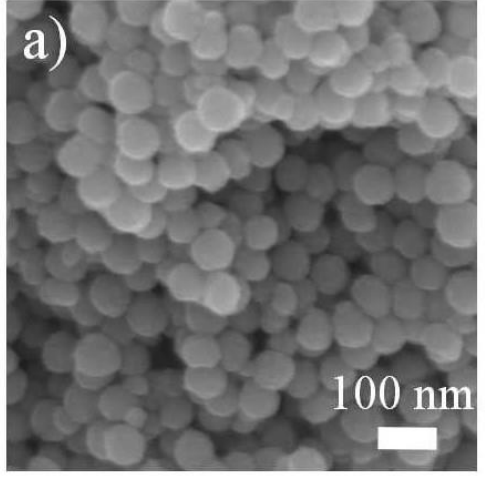

Amorphous Ni-P

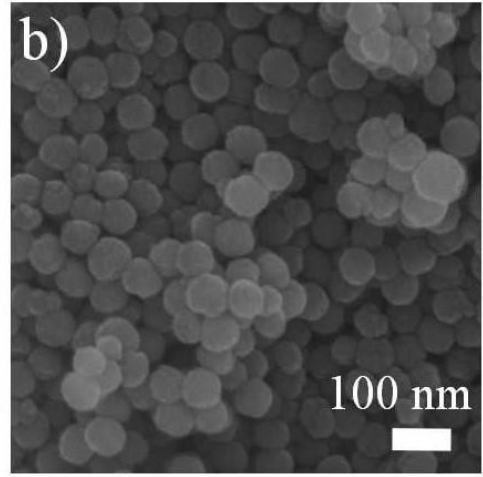

$\mathrm{Ni}_{3} \mathrm{P}-\mathrm{Ni}$

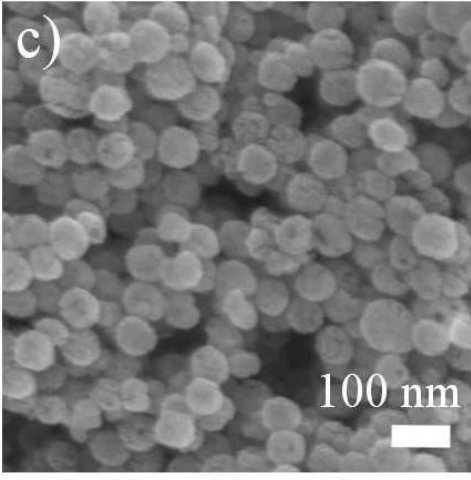

$\mathrm{Ni}_{3} \mathrm{P}$

Figure S2. SEM images of (a) amorphous $\mathrm{Ni}-\mathrm{P}$, (b) $\mathrm{Ni}_{3} \mathrm{P}-\mathrm{Ni}$, and (c) $\mathrm{Ni}_{3} \mathrm{P}$. 


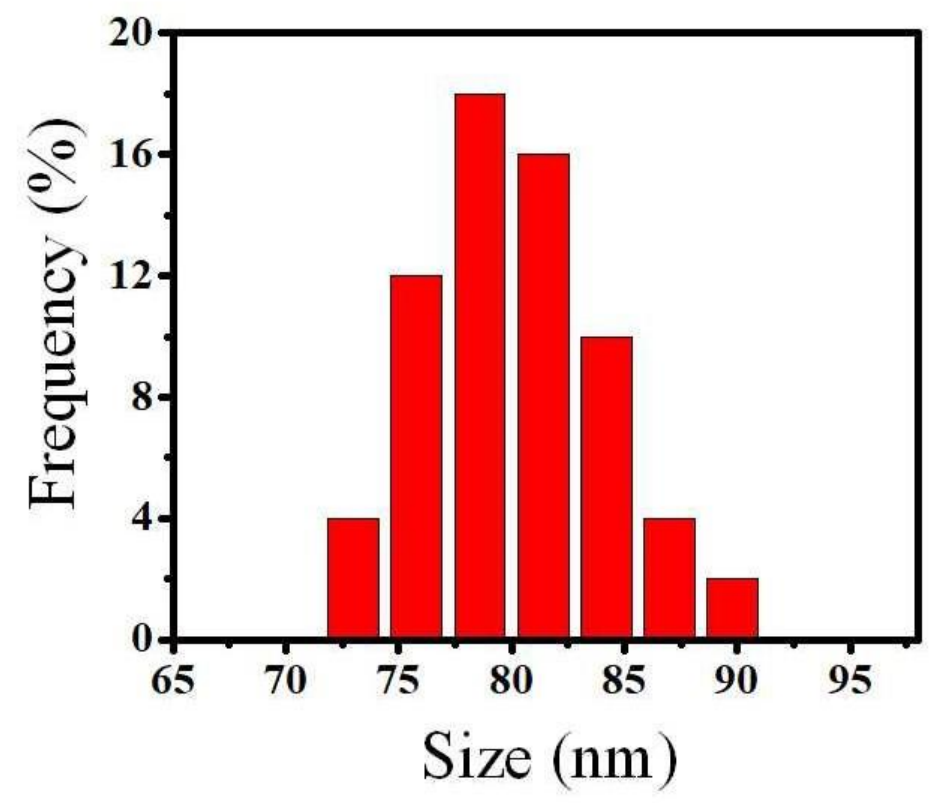

Figure S3. Size distribution histogram of NiP PHNPs.

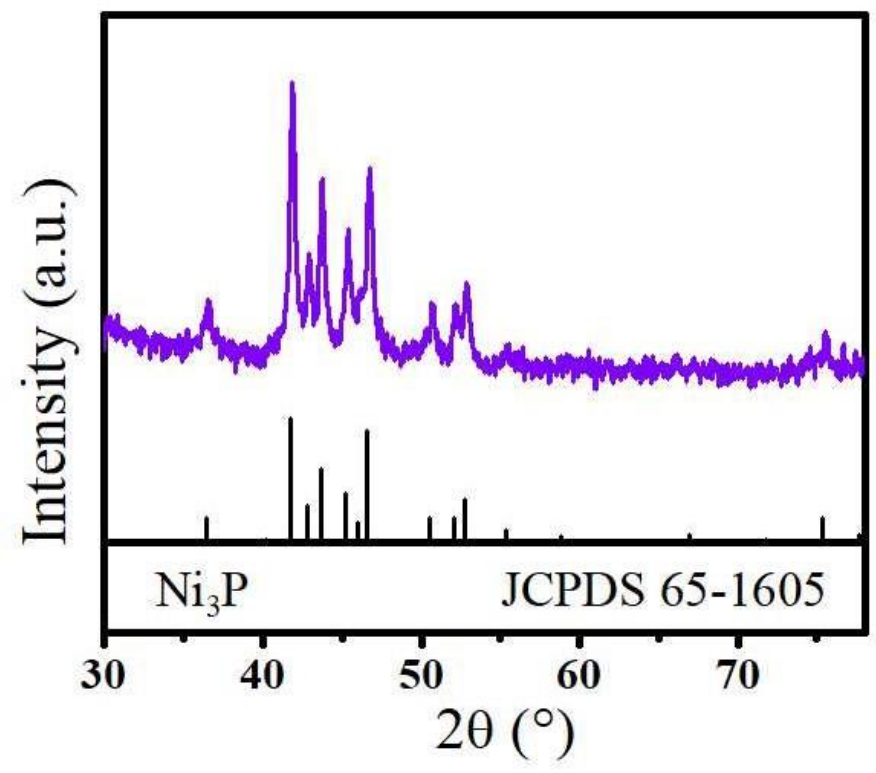

Figure $\mathbf{S 4}$. XRD of $\mathrm{Ni}_{3} \mathrm{P}$. 

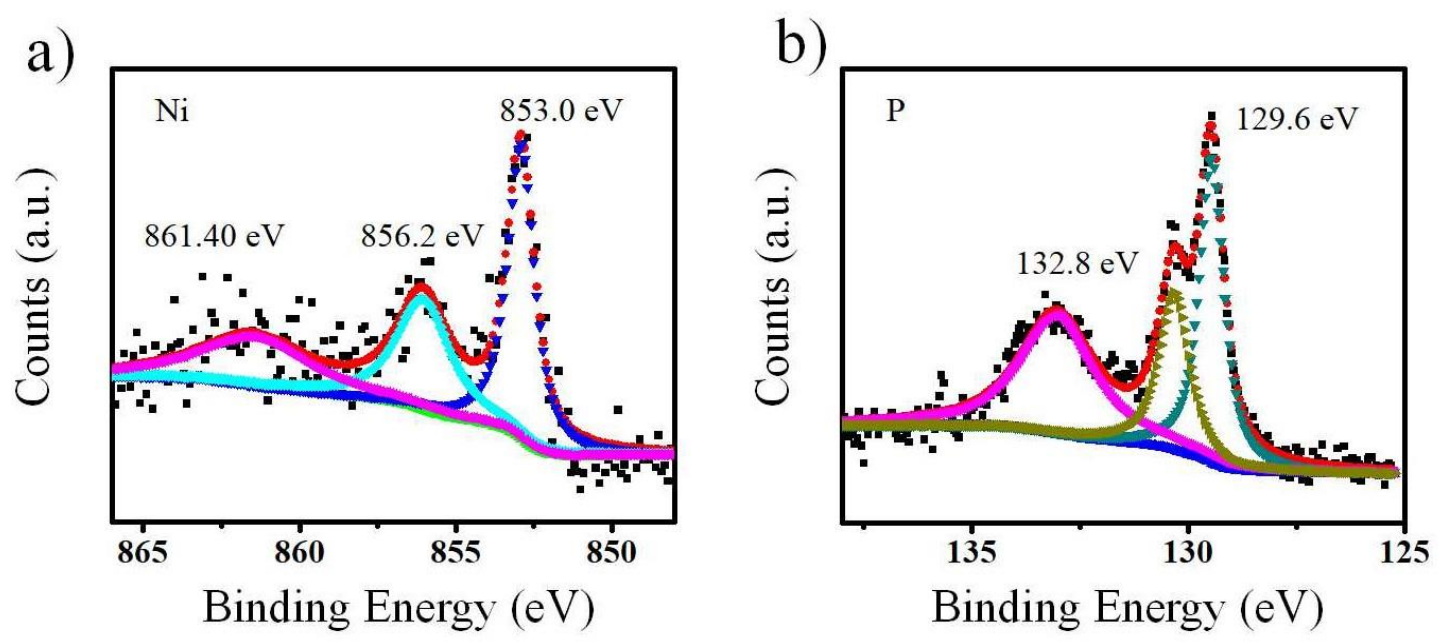

Figure S5. XPS of (a) Ni and (b) P.

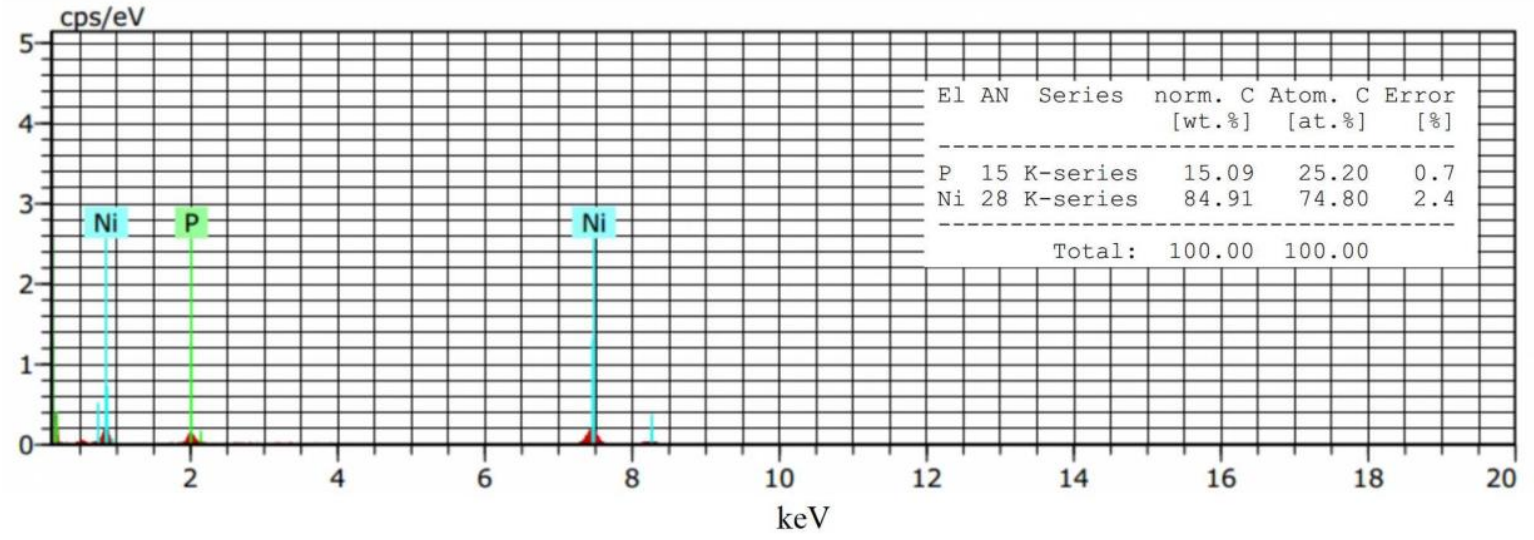

Figure S6. EDX of $\mathrm{Ni}_{3} \mathrm{P}$. 


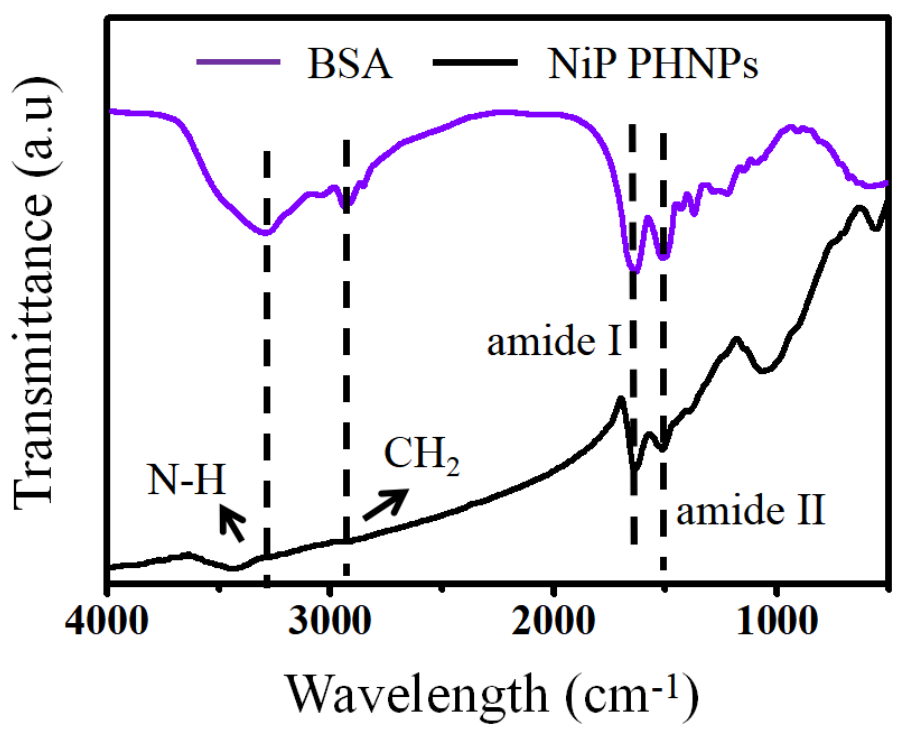

Figure S7. FT-IR spectra of BSA and NiP PHNPs.

a)

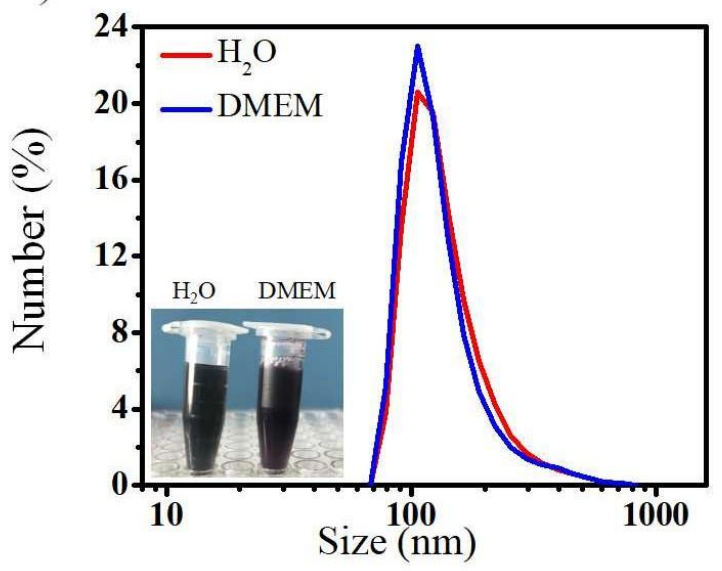

b)

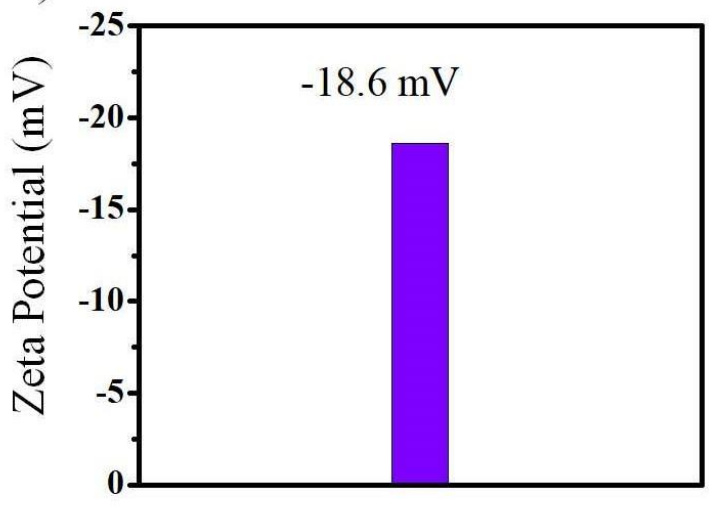

Figure S8. (a) Hydrodynamic size of NiP PHNPs in $\mathrm{H}_{2} \mathrm{O}$ and DMEM. Insets: photograph of NiP PHNPs in $\mathrm{H}_{2} \mathrm{O}$ and DMEM. (b) Zeta potential of NiP PHNPs. 


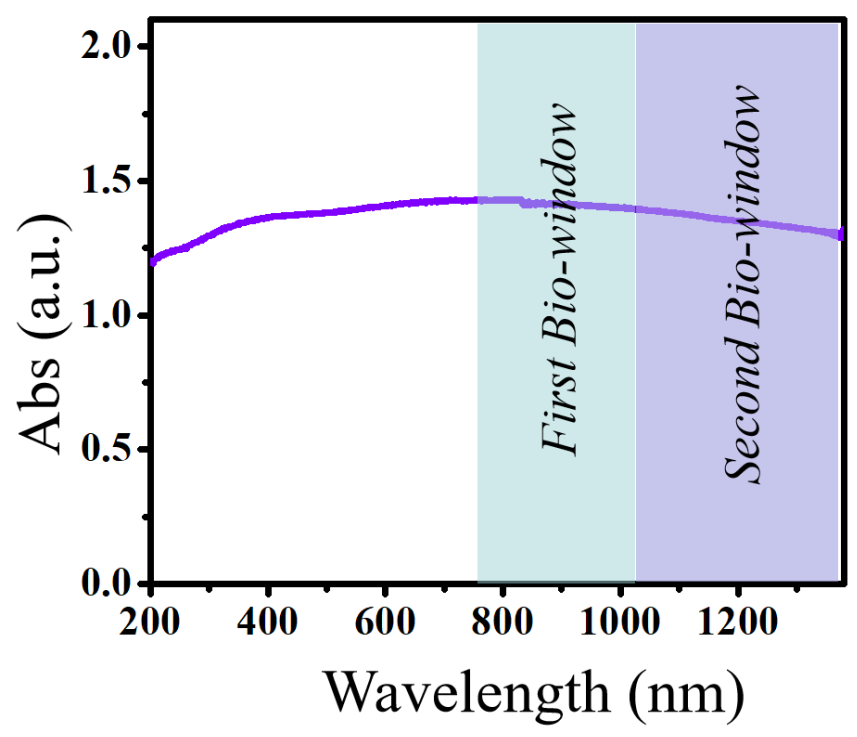

Figure S9. UV-vis absorption spectra of NiP PHNPs.
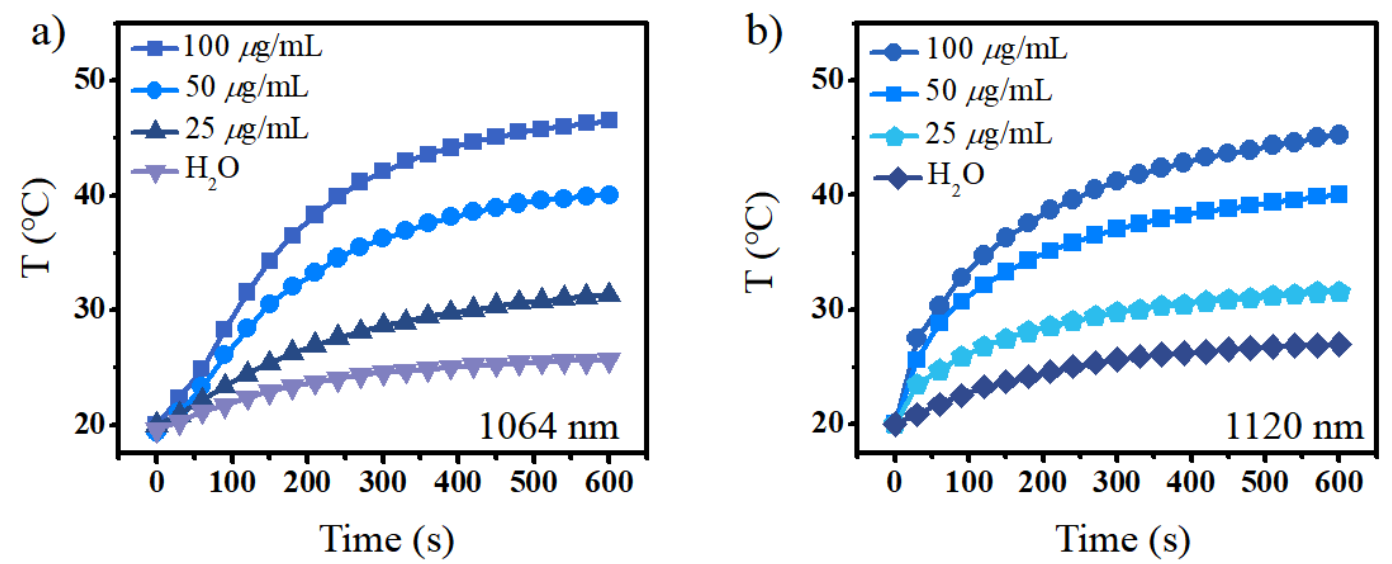

Figure S10. Temperature curves of different concentrations NiP PHNPs aqueous solution $\left(0,25,50\right.$, and $\left.100 \mu \mathrm{g} \mathrm{mL}^{-1}\right)$ under (a) $1064 \mathrm{~nm}\left(0.5 \mathrm{~W} \mathrm{~cm}^{-2}\right)$ and (b) 1120 $\mathrm{nm}$ laser $\left(0.5 \mathrm{~W} \mathrm{~cm}^{-2}\right)$ 


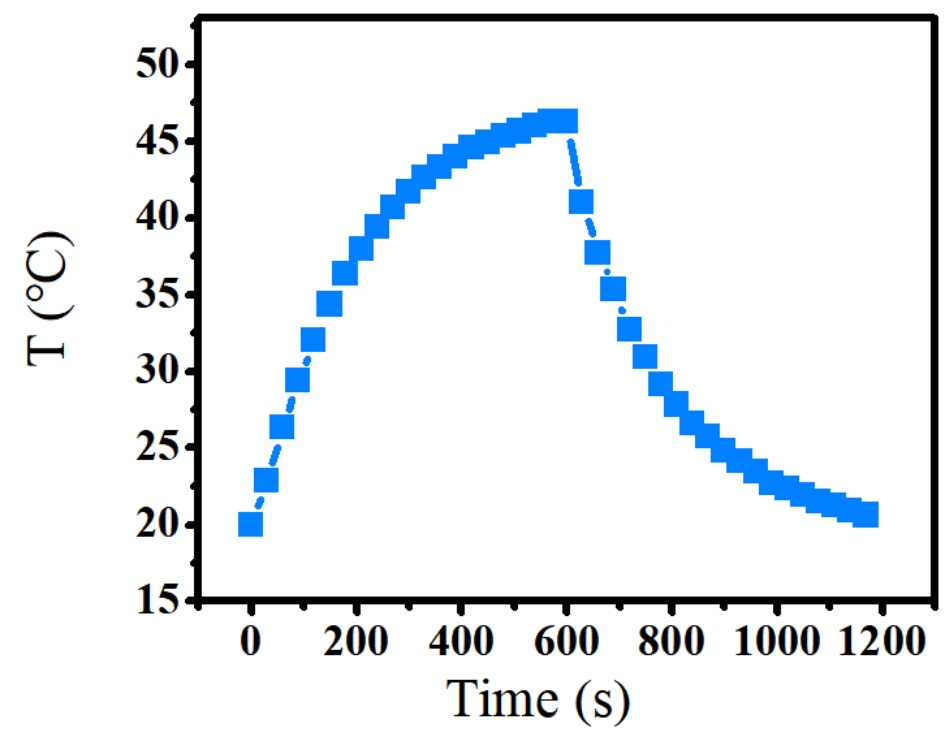

Figure S11. Heating and cooling curve of NiP PHNPs aqueous solution under 1064 $\mathrm{nm}$ laser irradiation $10 \mathrm{~min}$ and then stop.

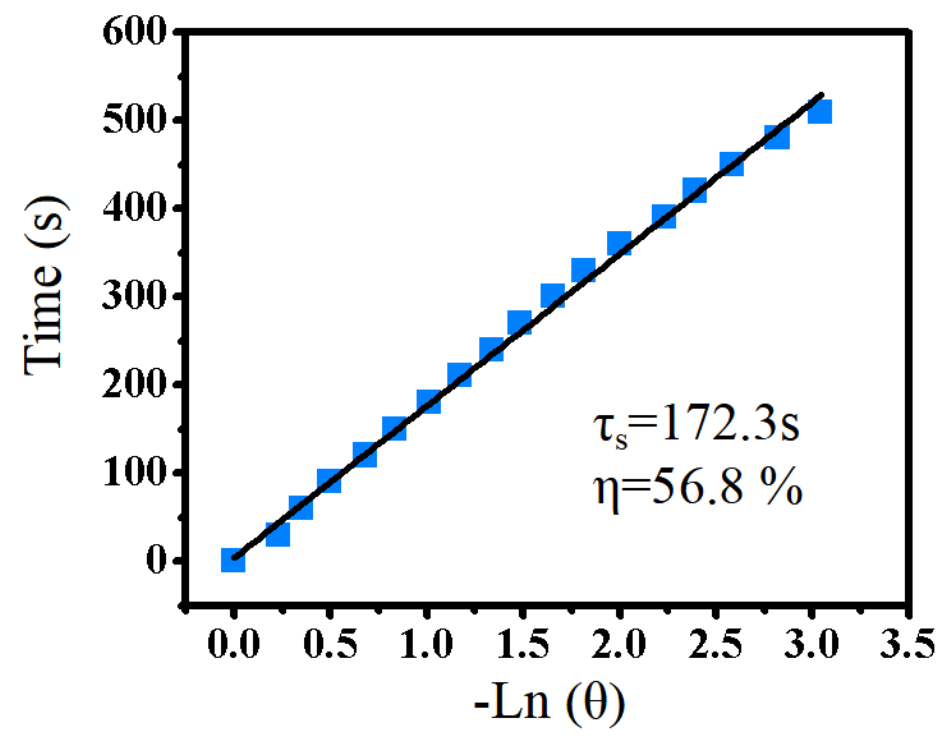

Figure S12. Linear time data obtained from the cooling period. 


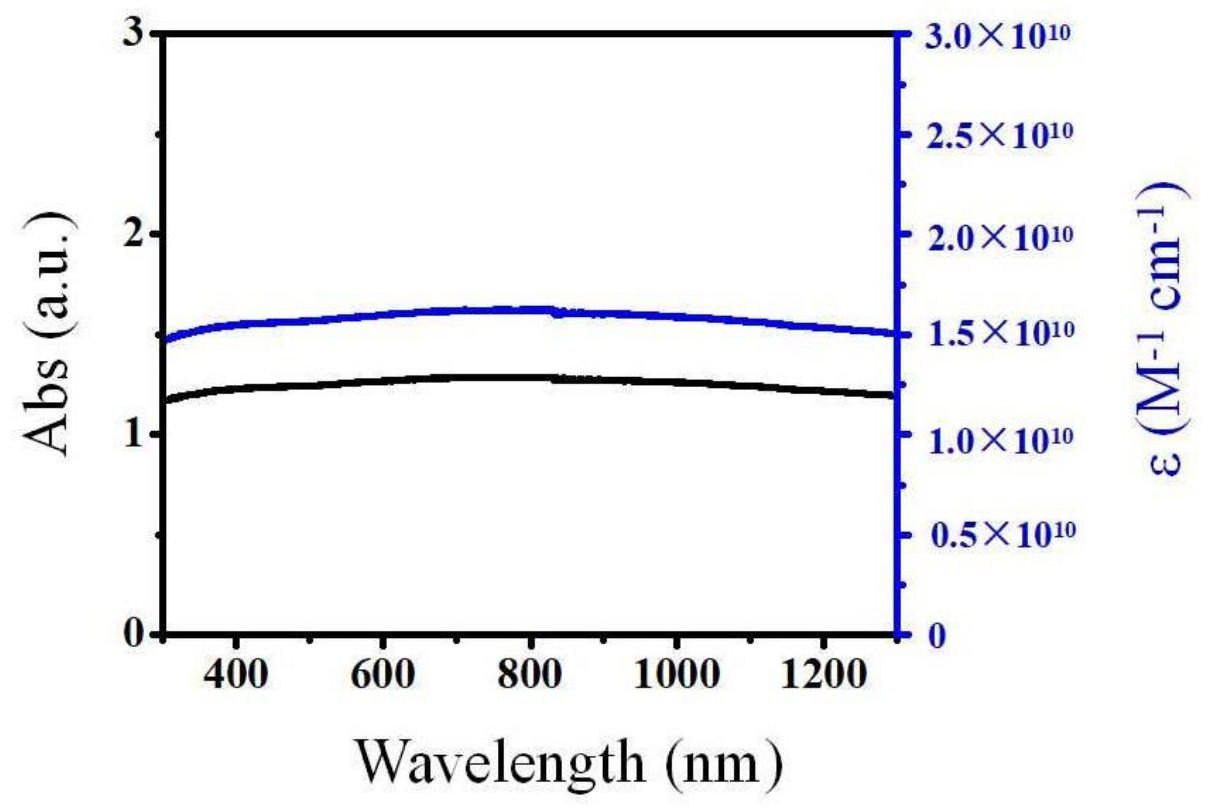

Figure S13. Molar extinction coefficient (blue line) of NiP PHNPs.

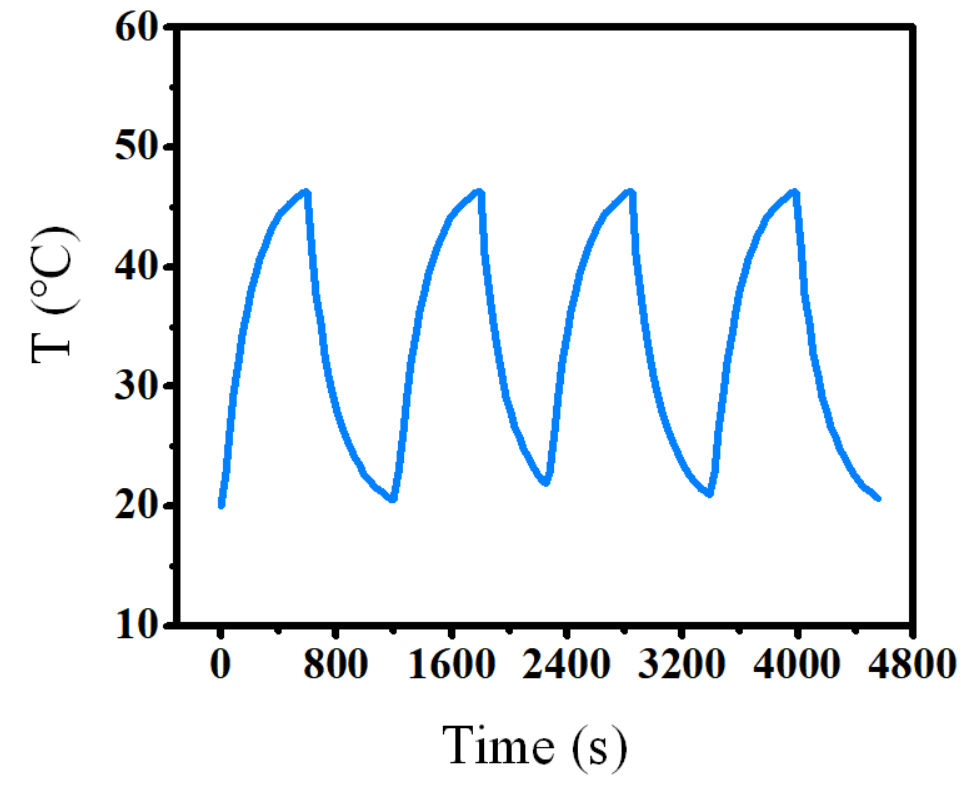

Figure S14. Temperature records of NiP PHNPs aqueous solution $\left(100 \mu \mathrm{g} \mathrm{mL}^{-1}\right)$ under four cycles of $1064 \mathrm{~nm}$ laser on/off at $0.5 \mathrm{~W} \mathrm{~cm}^{-2}$. 


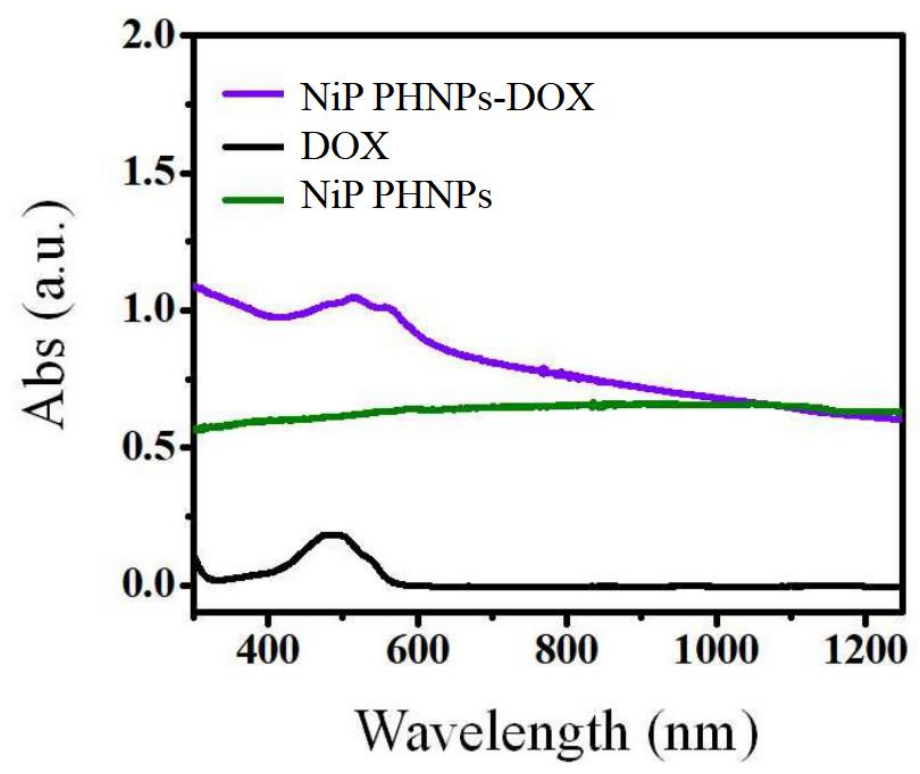

Figure S15. UV-vis absorption spectra of NiP PHNPs-DOX, DOX and NiP PHNPs.

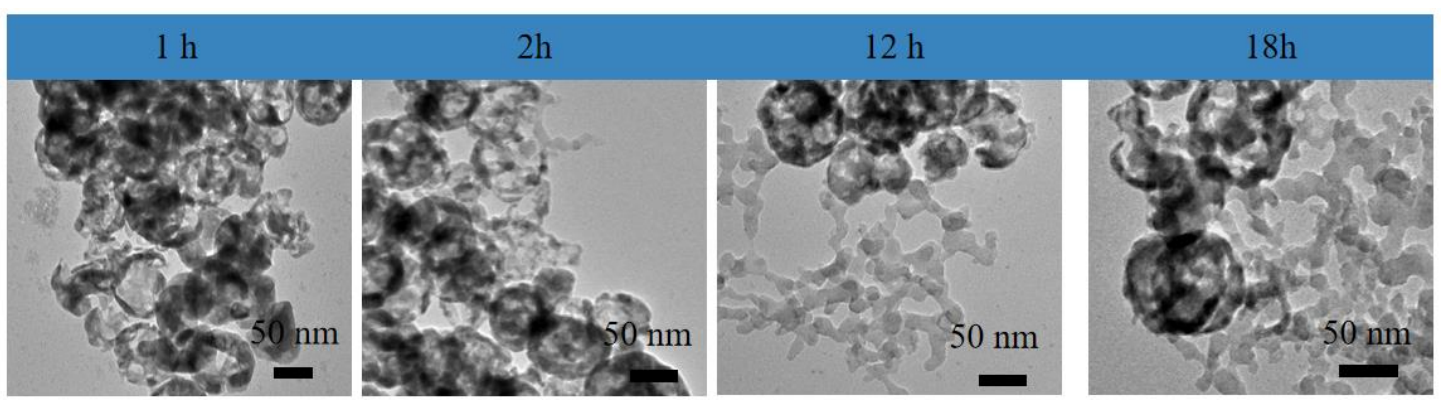

Figure S16. TEM image of NiP PHNPs in PBS solution (6.5) at different time points. 
a)

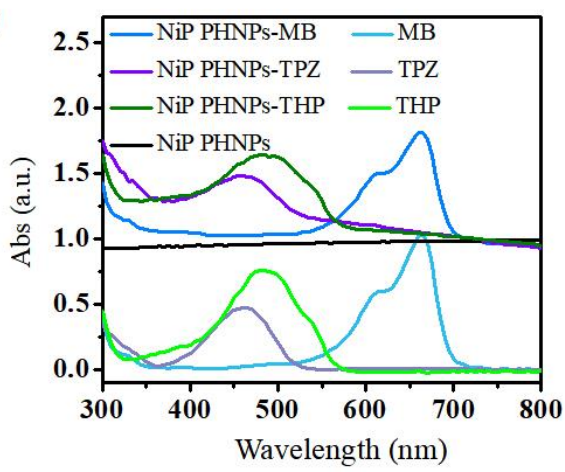

b)

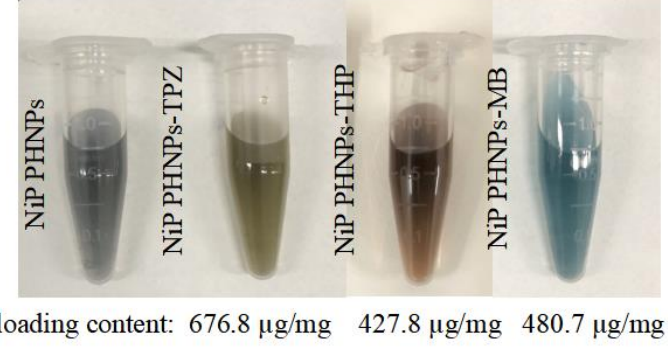

Maximum loading content: $676.8 \mu \mathrm{g} / \mathrm{mg} \quad 427.8 \mu \mathrm{g} / \mathrm{mg} \quad 480.7 \mu \mathrm{g} / \mathrm{mg}$

Figure S17. a) UV-vis absorption spectra of NiP PHNPs-MB, MB, NiP PHNPs-TPZ, TPZ, NiP PHNPs-THP, THP, and NiP PHNPs. b) Photograph of NiP PHNPs-MB, NiP PHNPs-TPZ, NiP PHNPs-THP, and NiP PHNPs.

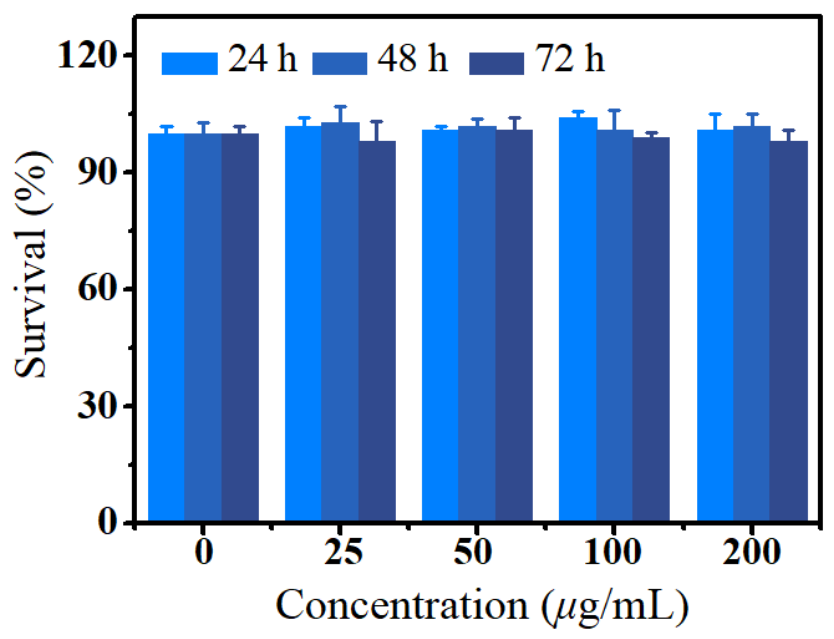

Figure S18. Cytotoxicity of NiP PHNPs to HeLa cells at 24 h, 48 h, and 72 h. 


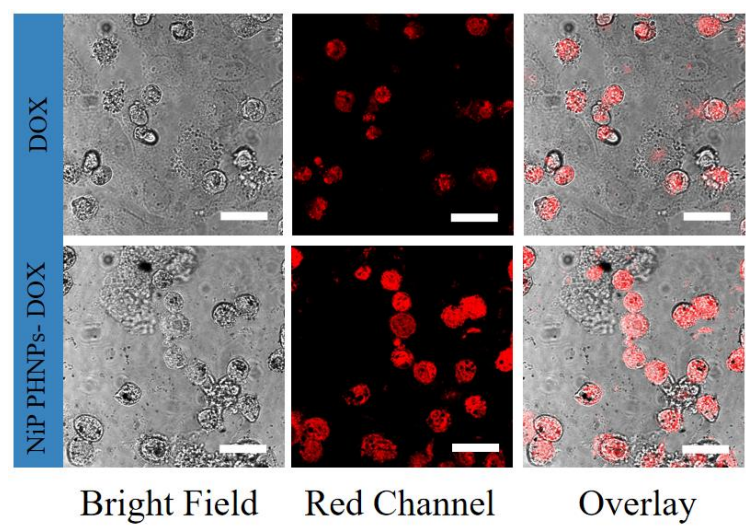

Figure S19. CLSM images of HeLa cells incubated with DOX and NiP PHNPs-DOX for $12 \mathrm{~h}$. All of the scale bars are $30 \mu \mathrm{m}$.

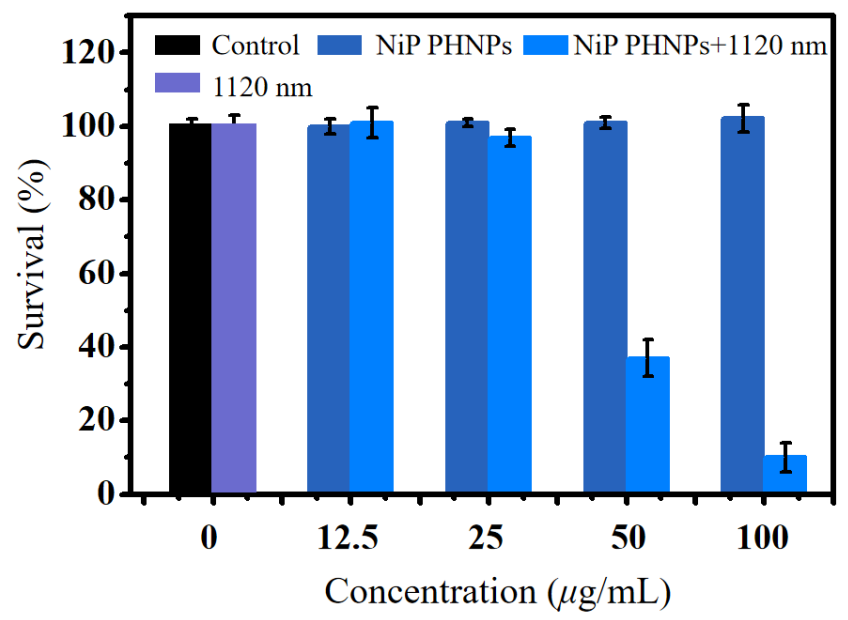

Figure S20. CCK-8 assay of HeLa cells after different treatments: (A) Control, (B) 1120 nm laser, (C) NiP PHNPs, and (D) NiP PHNPs + 1120 nm laser. 

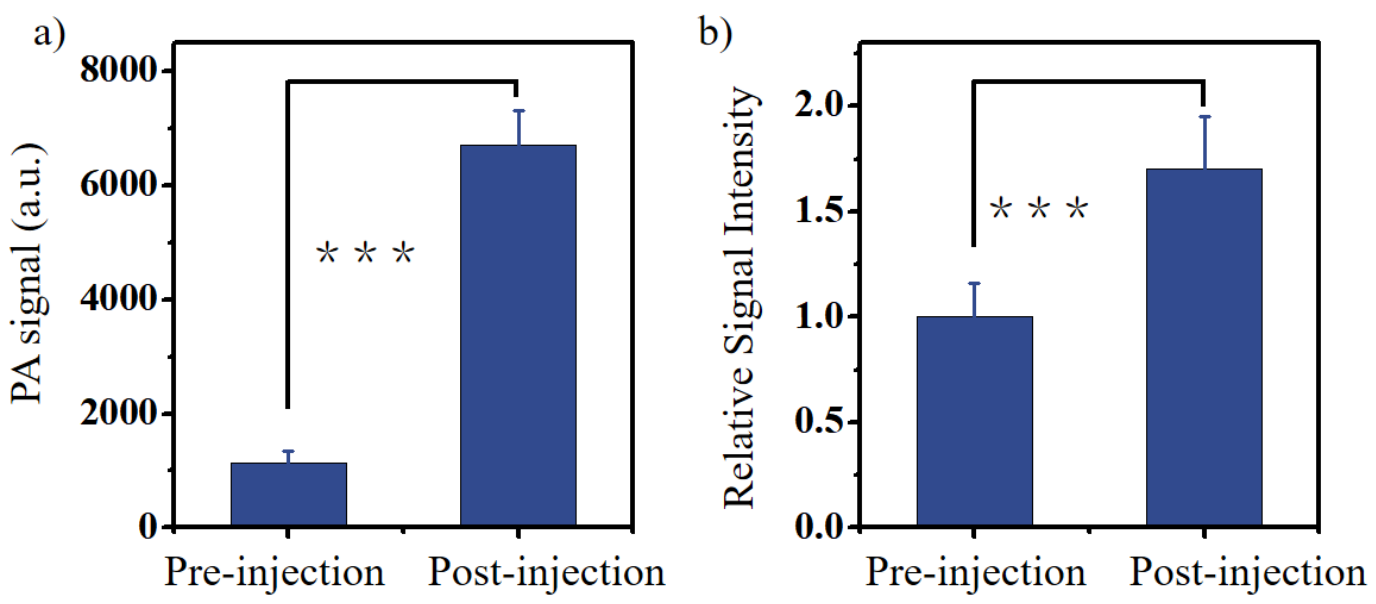

Figure S21. Quantification of a) PA, and b) MR signals in tumors after intravenous injection of NiP PHNPs in vivo.

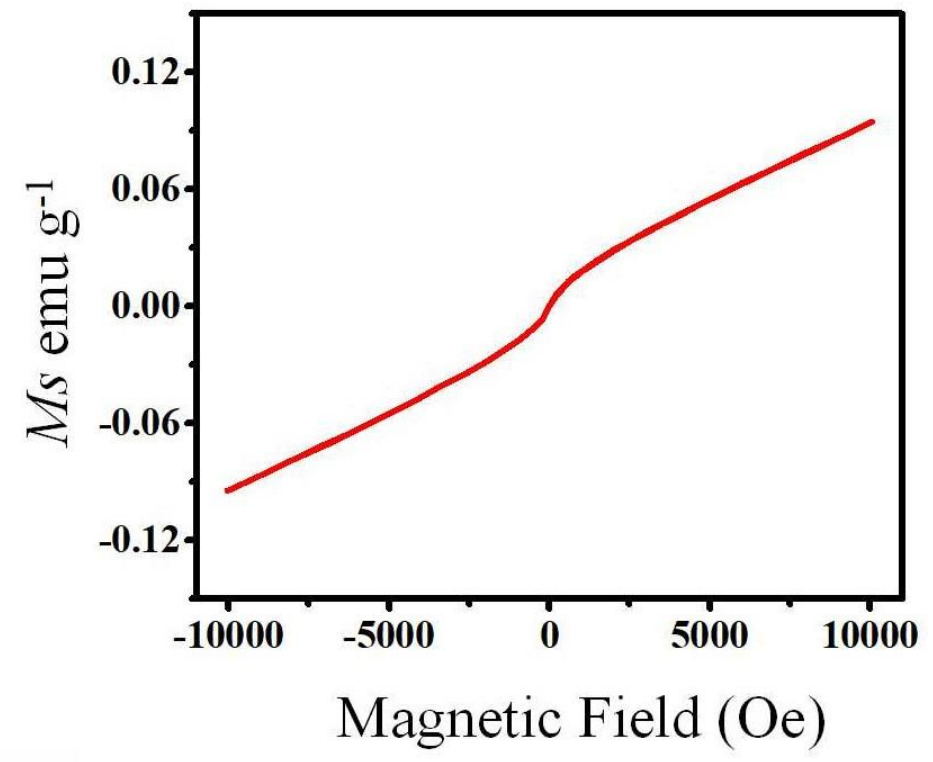

Figure S22. Magnetic hysteresis loop of the NiP PHNPs. 


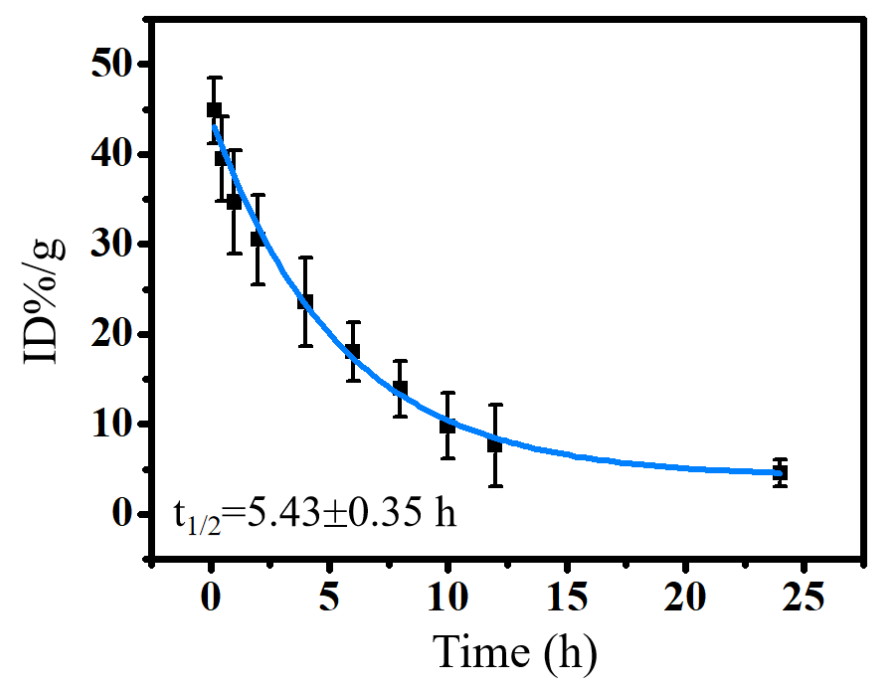

Figure S23. Blood circulation in mice treated with NiP PHNPs ( $n=3$, in each group) by evaluating content of $\mathrm{Ni}$ in blood at different time points $(10 \mathrm{~min}, 30 \mathrm{~min}, 1 \mathrm{~h}, 2 \mathrm{~h}$, 4h, 6h, 8h, 10h, 12h, and 24h) using ICP-AES.

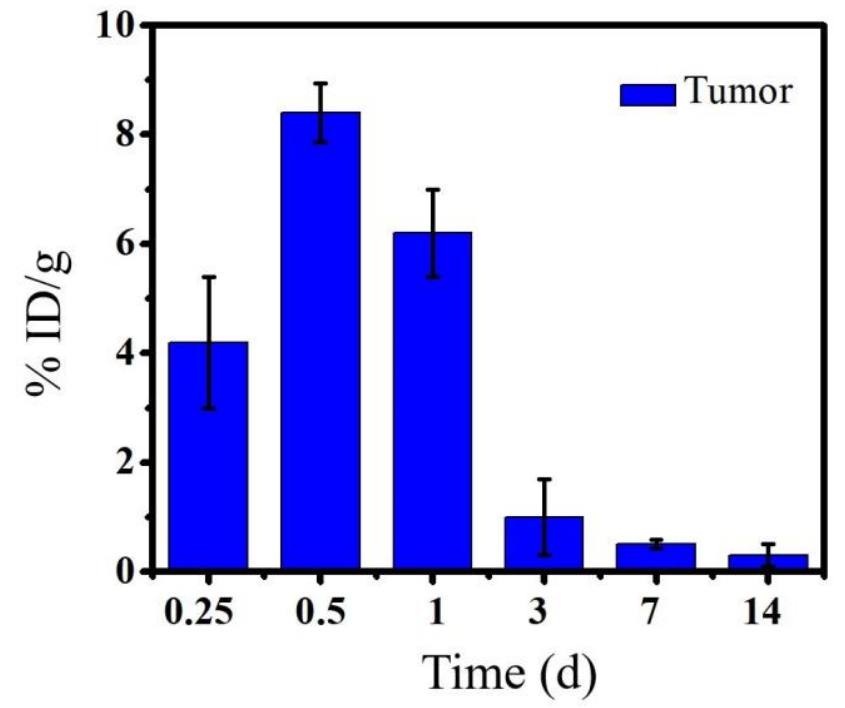

Figure S24. Biodistribution of $\mathrm{Ni}$ in tumor at different time $(0.25,0.5,1,3,7$, and 14 days). 


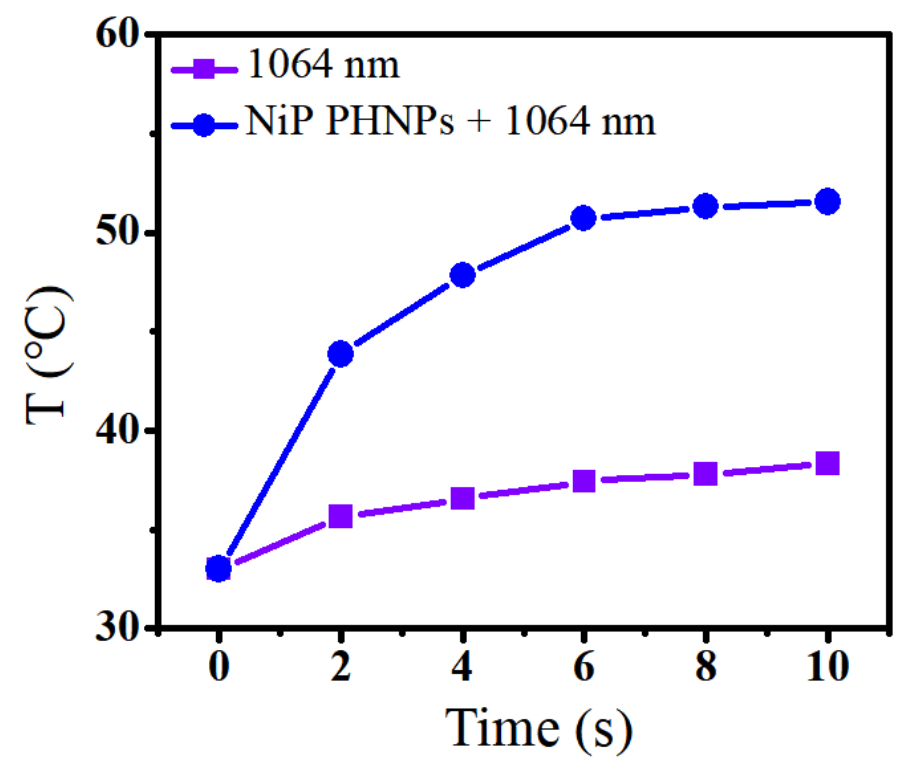

Figure S25. Temperature changes of tumors under the irradiation with $1064 \mathrm{~nm}(0.5$ $\mathrm{W} \mathrm{cm}^{-2}$ ).
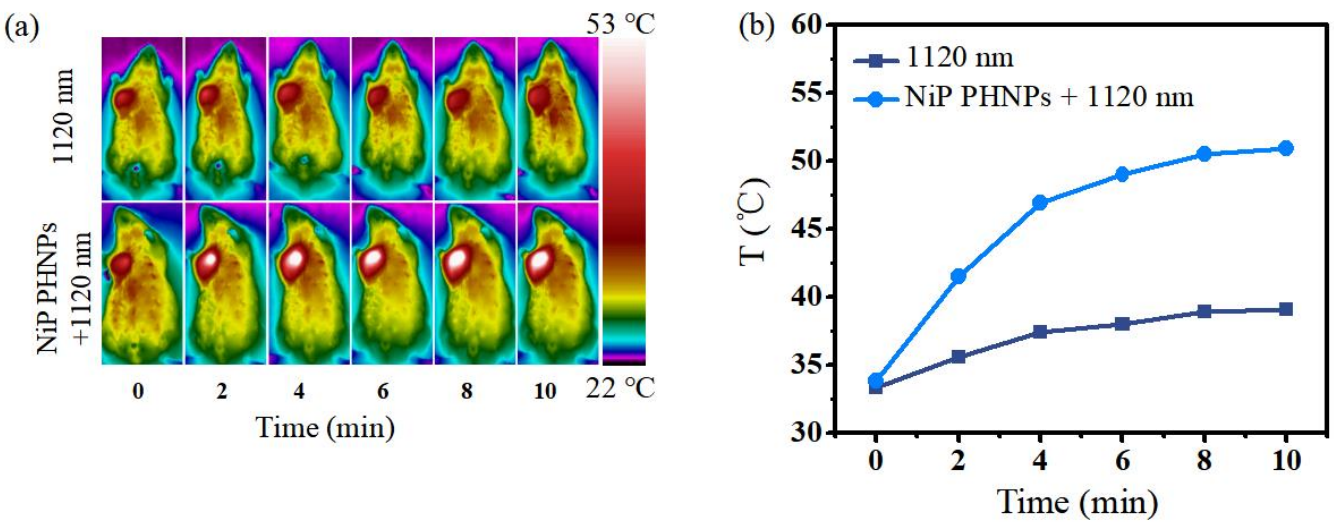

Figure S26. (a) Thermal imaging of tumor-bearing mice. (b) Temperature changes of tumors under the irradiation with $1120 \mathrm{~nm}\left(0.5 \mathrm{~W} \mathrm{~cm}^{-2}\right)$. 
(a)
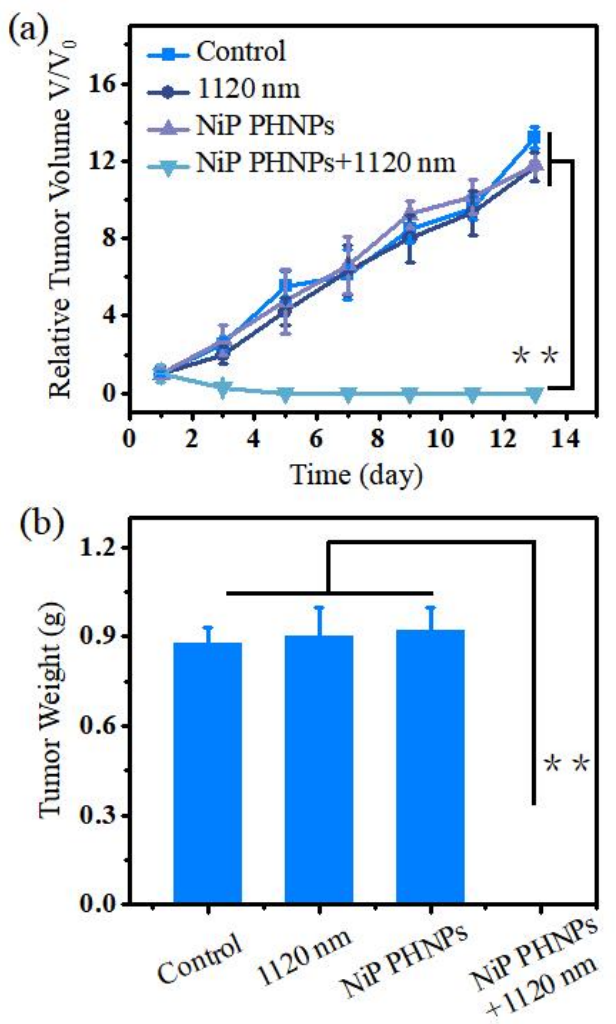

(c)

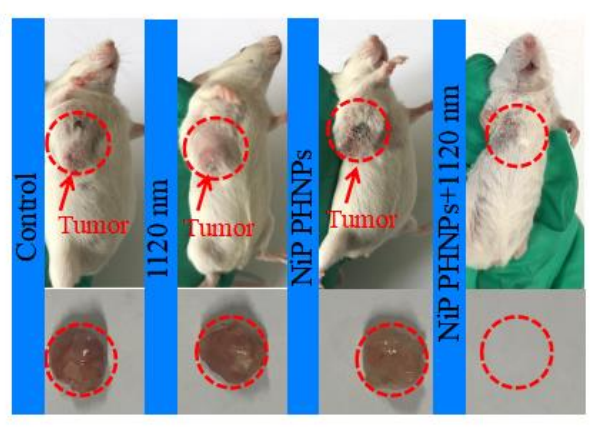

(d)

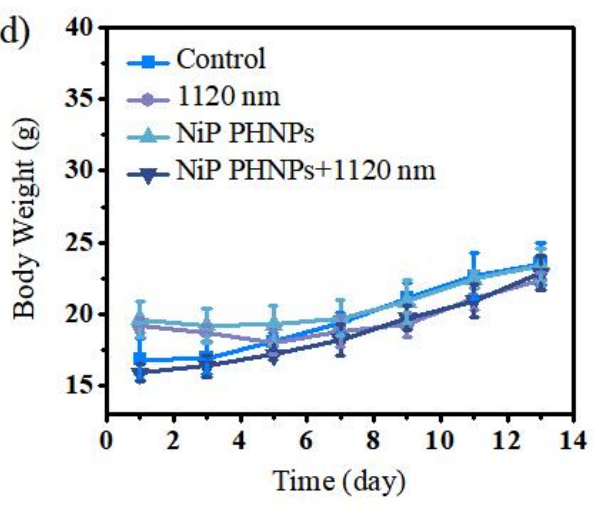

Figure S27. (a) Tumor volume curve ( $\mathrm{n}=5$, in each group) and (b) tumor weight histogram of mice: Control, $1120 \mathrm{~nm}$ Laser, NiP PHNPs, and NiP PHNPs + $1120 \mathrm{~nm}$ laser, ${ }^{*} p<0.05$ and ${ }^{*} p<0.01$ by student's two-tailed $t$ test. (c) Photos of mice and tumors. (d) Body weights of mice after different treatments. 

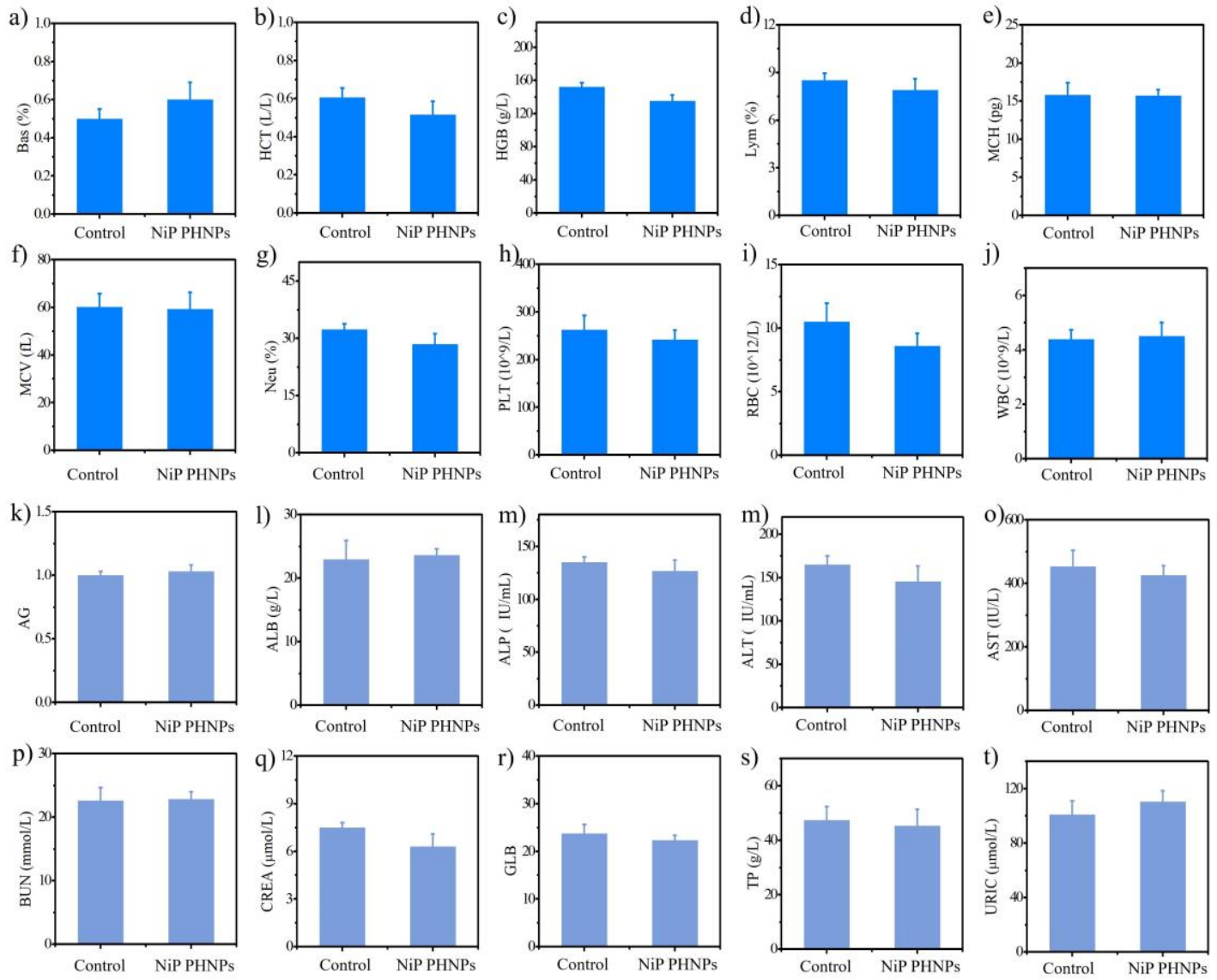

Figure S28. Blood analysis. (A-J) Hematology analysis detected by the complete blood after intravenous injection of NiP PHNPs at $30 \mathrm{~d}$. (K-T) Blood biochemistry detection by blood serum after intravenous injection of NiP PHNPs at $30 \mathrm{~d}$. 
Table S1. Photothermal performance of reported nanoagents.

\begin{tabular}{|c|c|c|c|}
\hline Materials & $\begin{array}{l}\text { Photothermal conversion } \\
\text { efficiency }(\eta, \%)\end{array}$ & Wavelength $(\lambda, \mathrm{nm})$ & Ref \\
\hline $\mathrm{Nb}_{2} \mathrm{C}$ & 36.5 or $45.65 \%$ & 808 or $1064 \mathrm{~nm}$ & S2 \\
\hline $\mathrm{Fe}_{3} \mathrm{O}_{4} @ \mathrm{CuS}$ & 15.7 or $19.2 \%$ & 808 or $1064 \mathrm{~nm}$ & S3 \\
\hline $\mathrm{B}-\mathrm{TiO}_{2-\mathrm{x}}$ & $39.8 \%$ & $1064 \mathrm{~nm}$ & S4 \\
\hline Ce6-labeled BSA-CuS & $29.8 \%$ & $1064 \mathrm{~nm}$ & S5 \\
\hline $\mathrm{NPs}\left[\mathrm{Ni}_{4} \mathrm{C}_{12}\right]$ & $26 \%$ & $940 \mathrm{~nm}$ & S6 \\
\hline $\mathrm{Ni}_{0.85} \mathrm{Se}$ & $54.06 \%$ & $808 \mathrm{~nm}$ & S7 \\
\hline $\mathrm{Ni}_{3} \mathrm{C} \mathrm{NCs}$ & $16.9 \%$ & $808 \mathrm{~nm}$ & S8 \\
\hline NiP PHNPs & $56.8 \%$ & $1064 \mathrm{~nm}$ & this work \\
\hline
\end{tabular}

Table S2. Molar extinction coefficient of reported nanoagents.

\begin{tabular}{|c|c|c|c|}
\hline Materials & $\begin{array}{l}\text { Molar extinction } \\
\text { coefficient }\end{array}$ & Wavelength $(\lambda, \mathrm{nm})$ & Ref \\
\hline BSA-IrO ${ }_{2}$ & $1.19 \times 10^{8} \mathrm{M}^{-1} \mathrm{~cm}^{-1}$ & $808 \mathrm{~nm}$ & $\mathrm{~S} 1$ \\
\hline Te-NDs & $2.14 \times 10^{9} \mathrm{M}^{-1} \mathrm{~cm}^{-1}$ & $808 \mathrm{~nm}$ & S9 \\
\hline $\mathrm{Cu}_{2-\mathrm{x}} \mathrm{Se}$ & $7.7 \times 10^{7} \mathrm{M}^{-1} \mathrm{~cm}^{-1}$ & $980 \mathrm{~nm}$ & $\mathrm{~S} 10$ \\
\hline $\mathrm{Cu}_{9} \mathrm{~S}_{5}$ & $1.2 \times 10^{9} \mathrm{M}^{-1} \mathrm{~cm}^{-1}$ & $980 \mathrm{~nm}$ & S11 \\
\hline $\begin{array}{l}\text { Nickel-bis(dithiolene) } \\
\text { complexes }\end{array}$ & $1.42 \times 10^{4} \mathrm{M}^{-1} \mathrm{~cm}^{-1}$ & $940 \mathrm{~nm}$ & $\mathrm{~S} 12$ \\
\hline Gold nanorods & $1.9 \times 10^{9} \mathrm{M}^{-1} \mathrm{~cm}^{-1}$ & $650 \mathrm{~nm}$ & $\mathrm{~S} 13$ \\
\hline NiP PHNPs & $1.577 \times 10^{10} \mathrm{M}^{-1} \mathrm{~cm}^{-1}$ & $1064 \mathrm{~nm}$ & this work \\
\hline
\end{tabular}




\section{References}

(1) Zhen, W.; Liu, Y.; Lin, L.; Bai, J.; Jia, X.; Tian, H.; Jiang, X. BSA-IrO2: Catalase-like Nanoparticles with High Photothermal Conversion Efficiency and a High X-ray Absorption Coefficient for Anti-inflammation and Antitumor Theranostics. Angew. Chem., Int. Ed. 2018, 57, 10309-10331.

(2) Lin, H.; Gao, S.; Dai, C.; Chen, Y.; Shi, J. A Two-Dimensional Biodegradable Niobium Carbide (MXene) for Photothermal Tumor Eradication in NIR-I and NIR-II Biowindows. J. Am. Chem. Soc. 2017, 139, 16235-16247.

(3) Wu, Z.; Li, W.; Luo, C.; Su, C.; Yeh, C. Rattle-Type Fe3O4@CuS Developed to Conduct Magnetically Guided Photoinduced Hyperthermia at First and Second NIR Biological Windows. Adv. Funct. Mater. 2015, 25, 6527-6537.

(4) Han, X.; Huang, J.; Jing, X.; Yang, D.; Lin, H.; Wang, Z.; Li, P.; Chen, Y. Oxygen-Deficient Black Titania for Synergistic/Enhanced Sonodynamic and Photoinduced Cancer Therapy at Near Infrared-II Biowindow. ACS Nano 2018, 12, $4545-4555$.

(5) Gao, D. Y.; Ji, X.; Wang, J. L.; Wang, Y. T.; Li, D. L.; Liu, Y. B.; Chang, K. W.; Qu, J. L.; Zheng, J.; Yuan, Z. Engineering a Protein-Based Nanoplatform as an Antibacterial Agent for Light Activated Dual-Modal Photothermal and Photodynamic Therapy of Infection in Both the NIR I and II Windows. J. Mater. Chem. B 2018, 6, 732-739.

(6) Ciancone, M.; Mebrouk, K.; Bellec, N.; Gaillard, C. L. G.; Bonnemains, Y. A.; Benvegnu, T.; Fourmigue', M.; Camerel, F.; Marion, S. C. Biocompatible Nanoparticles Containing Hydrophobic Nickel-Bis(dithiolene) Complexes for NIR-Mediated Doxorubicin Release and Photothermal Therapy. J. Mater. Chem. B 2018, 6, 1744-1753.

(7) Wang, X.; Li, F.; Yan, X.; Ma, Y.; Miao, Z.; Dong, L.; Chen, H.; Lu, Y.; Zha, Z. Ambient Aqueous Synthesis of Ultrasmall $\mathrm{Ni}_{0.85} \mathrm{Se}$ Nanoparticles for Noninvasive Photoacoustic Imaging and Combined Photothermal-Chemotherapy of Cancer. ACS Appl. Mater. Interfaces 2017, 9, 41782-41793. 
(8) Zhou, Z.; Wang, J.; Liu, W.; Yu, C.; Kong, B.; Sun, Y.; Yang, H.; Yang, S.; Wang, W. PEGylated Nickel Carbide Nanocrystals as Efficient Near-Infrared Laser Induced Photothermal Therapy for Treatment of Cancer Cells in Vivo. Nanoscale 2014, 6, 12591-12600.

(9) Yang, T.; Ke, H.; Wang, Q.; Tang, Y.; Deng, Y.; Yang, H.; Yang, X.; Yang, P.; Ling, D.; Chen, C.; Zhao, Y.; Wu, H.; Chen, H. Bifunctional Tellurium Nanodots for Photo-Induced Synergistic Cancer Therapy. ACS Nano 2017, 11, 10012-10024.

(10)Hessel, C. M.; Pattani, V.; Rasch, M.; Panthani, M. G.; Koo, B.; Tunnell, J. W.; Korgel, B. A. Copper Selenide Nanocrystals for Photothermal Therapy. Nano Lett. 2011, 11, 2560-2566.

(11)Tian, Q.; Jiang, F.; Zou, R.; Liu, Q.; Chen, Z.; Zhu, M.; Yang, S.; Wang, J.; Wang, J.; Hu, J. Hydrophilic $\mathrm{Cu}_{9} \mathrm{~S}_{5}$ Nanocrystals: A Photothermal Agent with a 25.7\% Heat Conversion Efficiency for Photothermal Ablation of Cancer Cells in Vivo ACS Nano 2011, 5, 9761-9771.

(12)Mebrouk, K.; Chotard, F.; Goff-Gaillard, C. L.; Arlot-Bonnemains, Y.; Fourmigue', M.; Camerel, F. Water-Soluble Nickel-Bis(dithiolene) Complexes as Photothermal Agents. Chem. Commun. 2015, 51, 5268-5270.

(13)Nikoobakht, B.; Wang, J.; El-Sayed, M. A. Surface-Enhanced Raman Scattering of Molecules Adsorbed on Gold Nanorods: Off-Surface Plasmon Resonance Condition. Chem. Phys. Lett. 2002, 366, 17. 